\title{
How learning misconceptions can improve outcomes and youth engagement with gambling education programs
}

\author{
BRITTANY KEEN*, FADI ANJOUL and ALEX BLASZCZYNSKI
}

School of Psychology, Faculty of Science, Brain and Mind Centre, The University of Sydney, Sydney, NSW, Australia

(Received: February 20, 2019; revised manuscript received: July 29, 2019; second revised manuscript received: August 29, 2019; accepted: September 1, 2019)

\begin{abstract}
Background and aims: Gambling education programs typically focus on promoting gambling as a high-risk activity with harmful effects; however, these programs demonstrate limited effects on the prevention of gambling problems. This paper proposes a clear theoretical framework to inform the content and delivery of gambling education initiatives and draws on psychological and pedagogical research to address some of the practical issues associated with its implementation. Methods: Literature was reviewed across fields of psychology, public health, and pedagogy to provide key recommendations to improve the outcomes of gambling education. Results: Four key recommendations were made for the development of future gambling education programs centering on theoretical approach, specialized content, and delivery. Discussion and conclusions: Recommended advancements are as follows: (a) evidence suggests shifting away from messages about gambling harms and instead applying a cognitive-developmental framework of problem gambling that may improve youth engagement by increasing personal relevance. (b) The cognitive model of problem gambling suggests that misconceptions about the profitability of gambling games (e.g., the gambler's fallacy) play an important role in the development of problems and should be a key target for education. However, exposing such misconceptions requires the challenge of teaching the mathematical principles that underpin them. (c) The pedagogical field provides valuable insights into teaching complex concepts. Research that applies the conceptual change model to science education suggests misconceptions also facilitate learning new complex information, such as gambling-related mathematical concepts (i.e., randomness and statistics). (d) In addition, improvements in computer-assisted teaching methods provide opportunities to use simulations and visualizations to help teach abstract concepts and correct such misconceptions.
\end{abstract}

Keywords: gambling, education, prevention, misconceptions, cognitive distortions, adolescents

\section{INTRODUCTION}

Most individuals are first exposed to gambling experiences during adolescence (Delfabbro, Lahn, \& Grabosky, 2005; Delfabbro, Lambos, King, \& Puglies, 2009; Delfabbro, Winefield, \& Anderson, 2009; Purdie, Matters, Hillman, Ozolins, \& Millwood, 2011; Splevins, Mireskandari, Clayton, \& Blaszczynski, 2010). Several research studies report problem gambling rates among adolescents to be 3-10 times higher than those found in adults (Derevensky \& Gupta, 2000; Gupta et al., 2013; Purdie et al., 2011; Splevins et al., 2010; Welte, Barnes, Tidwell, \& Hoffman, 2008). Despite criticism that the current rates are inflated (Derevensky, Gupta, \& Winters, 2003; Stinchfield, 2010), adolescents represent a subpopulation of interest to those tasked with the objective of preventing development of future gambling problems.

\section{Gambling education programs for adolescents and young adults}

Consistent with efforts to prevent harm from other risky behaviors, such as alcohol and substance use, sexual activity, and recklessly operating a motor vehicle (Bachman et al., 2008; Noar, Palmgreen, Chabot, Dobransky, \& Zimmerman, 2009; Vivancos, Abubakar, Phillips-Howard, \& Hunter, 2013), educational initiatives have been developed to encourage awareness of risks, informed choice, and ultimately good decision-making when gambling (see Keen, Blaszczynski, \& Anjoul, 2016; Ladouceur, Goulet, \& Vitaro, 2013 for reviews).

The primary purpose of educational strategies is to disseminate accurate information with the aim of fostering informed choice and responsible gambling among future gamblers (Keen et al., 2016; Ladouceur et al., 2013; Monaghan, 2008). The nature of the information contained in these educational programs varies. Most programs generally raise awareness of gambling as a risky behavior and detail the dangers of excessive gambling. Some focus on teaching young people about the unfair nature of gambling games, including information about how outcomes are determined

\footnotetext{
* Corresponding author: Brittany Keen; School of Psychology, Faculty of Science, Brain and Mind Centre, The University of Sydney, 94 Mallett Street, Camperdown 2050, NSW, Australia; Phone: +61 29114 4373; Fax: +61 29036 5223; E-mail: Brittany. keen@sydney.edu.au
}

This is an open-access article distributed under the terms of the Creative Commons Attribution-NonCommercial 4.0 International License, which permits unrestricted use, distribution, and reproduction in any medium for non-commercial purposes, provided the original author and source are credited, a link to the CC License is provided, and changes - if any - are indicated. 
randomly and the low probability of winning. Others include strategies for gambling within financial limits, budget management, and myths and misconceptions related to gambling games (Keen et al., 2016; Ladouceur et al., 2013; Monaghan, 2008).

Typically, educational programs designed to prevent gambling-related harm are aimed at adolescents or young adults who have not yet gambled or are in the early stages of gambling experiences. Educational programs for adolescents are often implemented in school settings, as they represent appropriate sites for dissemination of information to young people in society (Monaghan, 2008). Several programs have also been implemented and evaluated in university (college) settings among young adults. These are more common in countries such as the United States where the legal age to gamble is slightly higher (21 years old) and so access to gambling coincides with admittance to college. However, school-based programs are more common in countries like Australia, where many young people have access to commercial gambling opportunities while still attending secondary school (18 years old).

A recent systematic review demonstrated that the vast majority of school-based education programs with adolescents tends to focus on raising awareness of the potential risks and harmful outcomes that may eventuate from gambling (Keen et al., 2016), and so these will accordingly be referred to as "risk-awareness" programs. Such approaches can be described as encapsulating fear-based messaging designed to deter recipients from engaging in the described behavior to avoid potential harmful consequences.

\section{Efficacy of gambling education as a preventative strategy}

Educational programs may be conceived as a demandreduction strategy by encouraging informed decisionmaking among individuals. However, such education competes against the overwhelming volume of advertisements from the gambling industry encouraging people to gamble regularly as well as easy access to many gambling opportunities. The purpose of educational programs may be better conceptualized as promoting informed choice in line with a suite of broader preventative measures including regulation, legislation, and key stakeholder responsibilities.

Three recent reviews of the content, design, evaluation, and efficacy of educational gambling programs for adolescents and young adults suggest that improvements in gambling knowledge, attitudes, and reductions in misconceptions are common; however, the impact of these outcomes is rarely translated into behavioral changes (Keen et al., 2016; Ladouceur et al., 2013; Oh, Ong, \& Loo, 2017). These reviews suggest that educational programs to date have had limited success in preventing young people from developing gambling problems. The Productivity Commission (2010) commented on the limited efficacy of current educational programs due to their inability to produce behavioral change among participants. The report went so far as to say, "... school-based information programs could be having perverse effects and should not be extended without review" (2010, p. 3).

However, it is not clear exactly what kind of information should be taught to have optimal impact on young people's decision-making. The reasons why changes in knowledge, attitudes, and misconceptions have not led to behavioral outcomes are not clear, but possible suggestions are that (a) these variables are not important in predicting gambling behavior; (b) the impact of the educational effects are not strong enough to translate into behavioral outcomes; or (c) measures of gambling knowledge, attitudes, and misconceptions lack validity and real effect sizes are smaller than those reported and intervention effects need boosting to affect behavior.

The apparent lack of effectiveness may relate to either delivery approach or content. Several current programs are perhaps delivered in a way that falls short or could be improved upon using more innovative and technologically advanced strategies (Borovcnik, 2007; Chandra \& Watters, 2012; McKagan et al., 2008). Another explanation may be that the general content focusing on raising awareness about the risks or dangers of excessive gambling may not resonate with young audiences.

\section{The current review}

The purpose of this paper is to provide new insights into improving engagement with gambling education among young people, and to detail some of the conceptual and practical barriers in pursuing new directions to prevent gambling problems. This paper justifies the need for more theory-driven and evidenced-based content in gambling education programs to enhance their efficacy in reducing gambling-related harm.

It proposes that the cognitive model of problem gambling represents a conceptually justifiable theoretical framework to inform the content and delivery of gambling education initiatives. It then brings together psychological research and theory to inform how educational content might be developed and implemented using this framework. We explore some of the reported and anticipated issues of applying such a framework in practice and draw upon the pedagogical literature for solutions to common problems.

Specifically, this paper articulates the dual purpose for incorporating misconceptions into gambling education both conceptually and practically. From a conceptual perspective, misconceptions contribute to the development of problem gambling progressively by further motivating bets after losses. This developmental framework of problem progression may encourage young people to better identify themselves as someone who may be vulnerable to developing the disorder (enhancing engagement and relevance).

From a practical perspective, there are two main benefits of incorporating misconceptions into gambling education. The first as stated above is that misconceptions are known risk factors for gambling problems, so it is important to address and correct unhelpful thinking patterns early, so that we might reduce their impact on motivating current and future gambling play. A strong understanding of key mathematical concepts that pertain to gambling games may assist in addressing such misconceptions and act as a protective factor for their development.

Finally, the pedagogical literature states that misconceptions in many different fields of science education serve as 


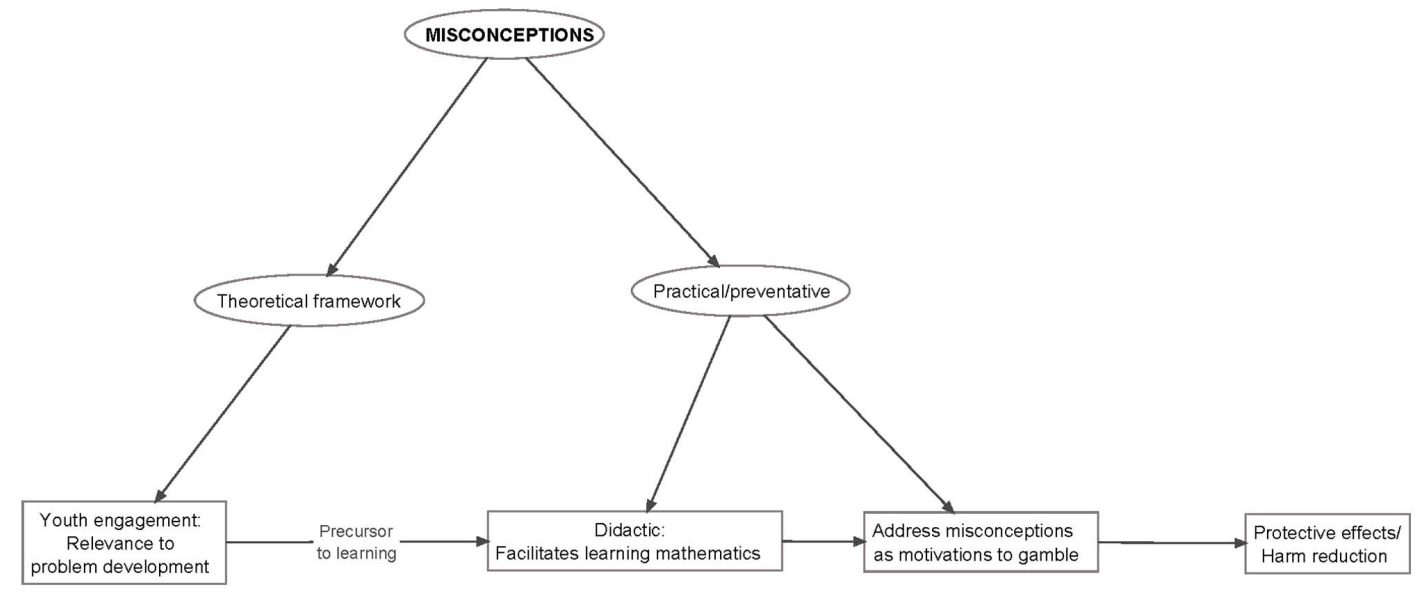

Figure 1. The proposed rationale for emphasizing misconceptions in gambling education

important didactic teaching tools. When young people learn about how others have misinterpreted new concepts, they are less likely to make these mistakes themselves and are better able to learn complex material like gambling mathematics more accurately. The multiple advantages to incorporating misconceptions into gambling education are presented in Figure 1.

The paper is separated into four sections, each of which constitutes recommended changes to the theoretical approach, content, and delivery of gambling education: (a) emphasizing the harms of excessive gambling may not be relevant to youth and should be avoided; (b) adopting a cognitive-developmental framework that focuses on the importance of gambling misconceptions may be a more engaging approach for young people; (c) teaching gambling-related mathematics may act as a protective factor for gambling problem development and pedagogical research that suggests explanations of misconceptions also plays a didactic role and may improve this learning process; and (d) technology can help promote a deeper understanding of complex gambling mathematics using data visualizations and simulations. These recommendations and the theoretical and scientific literature that supports them are provided below.

\section{RECOMMENDATION 1: SHIFT THE FOCUS AWAY FROM HARMS TO INCREASE YOUTH ENGAGEMENT}

Current risk-awareness programs for gambling may be less engaging for young people because they generally omit mechanistic explanations of the disorder, which link the target audience to development of the disorder and associated consequences. Risk-awareness programs typically depict a person (usually an adult) suffering a range of severe gambling-related harms (divorce, mortgage repayments, job loss, bankruptcy, etc.) and need professional help. Given that prevention, by its nature, targets non-gamblers and non-problem gamblers, it would appear that these messages describe a situation that inherently does not relate to the target audience. As a consequence, the audience are then more likely to attribute such problems to someone unlike themselves (Hastings, Stead, \& Webb, 2004), which reduces relevance and personal engagement with the message (Goldberg, Bents, Bosworth, Trevisan, \& Elliot, 1991; Higbee, 1969; Martin \& Kamins, 2010).

These types of programs educate learners about the negative consequences of gambling problems, but do not provide an explanation of the factors that influence how or why problems emerge. This has likely been influenced by the considerable ambiguity in the gambling field around how problems develop (McIntosh, 2017; Rickwood, Blaszczynski, Delfabbro, Dowling, \& Heading, 2010). The lack of a clear and unified theoretical model for problem gambling has likely hindered the standardized inclusion of a detailed description of problem formation in educational programs, as well as a clear mechanistic target for prevention.

Based on this reasoning, it is possible that the inclusion of a developmental account of gambling problem formation may enhance personal relevance and engagement for young people. Instead of encouraging concern for end consequences, a developmental account places emphasis on transitional processes that may occur between progressive stages of gambling. The information presented would educate on how someone progresses from initial exposure to recreational gambling and to problem gambling. The target audience, who are either non-gamblers or non-problem gamblers, may find information relating to problem development and has more personal relevance, that is a key to increase learner engagement and understanding of new educational material (Heddy \& Sinatra, 2013; Shernoff, Csikszentmihalyi, Schneider, \& Shernoff, 2003; Taylor \& Parsons, 2011).

It appears then that programs aiming to promote messages about the harmful and severe consequences of gambling have limited effectiveness in preventing future gambling problems, possibly because adolescents dismiss such messaging as lacking personal relevance or because they are not applicable to them. Therefore, it is proposed programs that account for how someone much like themselves (presumably a non-gambler) might engage in gambling activities and perhaps develop future problems and might increase personal relevance, engagement, and impact on adolescents. 


\section{RECOMMENDATION 2: APPLY A COGNITIVE-DEVELOPMENTAL APPROACH TO GAMBLING EDUCATION}

One theoretical model that provides a developmental account of problem gambling is the cognitive model. Cognitive theories of problem gambling predominantly focus on the role that misguided belief systems to play in driving gambling behavior (Ladouceur \& Walker, 1996). Cognitive therapeutic techniques typically involve challenging and replacing unhealthy cognitions with more accurate and helpful ones (Chretien, Giroux, Goulet, Jacques, \& Bouchard, 2017). Within the literature, gambling cognitions have been referred to using various terminologies; cognitive distortions, erroneous cognitions, irrational, or distorted beliefs; and misconceptions, to name a few (see Chretien et al., 2017 for a systematic review). Attempts to measure such cognitions have also been varied and inconsistent (see Barrault \& Varescon, 2012 for a comprehensive list of gambling cognition measures). A specific advantage of applying a cognitive-developmental model of problem gambling development to educational efforts over and above other developmental models (neurodevelopmental, behavioral, etc.) is that it suggests modification of thoughts and beliefs via didactic strategies, which may act as protective factors for gambling problems. It has also been suggested that focusing on cognitive mechanisms of change in public health may be more appropriate than focusing on behavioral solutions as the former better predicts gambling behavior (Yakovenko et al., 2016). The results from longitudinal research indicate that gambling-related misconceptions may be the earliest robust predictors of change from social to problematic gambling, and thus should be the target for prevention initiatives (Yakovenko et al., 2016).

In the late 1980s, Gaboury and Ladouceur (1989) utilized the "talk-aloud" approach, which involves asking gamblers to verbalize their thought processes as they engage in gambling tasks or activities. Research using this method has established that gamblers consistently demonstrate systematic thinking errors (misconceptions) while gambling (Baboushkin, Hardoon, Derevensky, \& Gupta, 2001; Delfabbro \& Winefield, 2000; Gaboury \& Ladouceur, 1989; Griffiths, 1994; Walker, 1992a).

For the purposes of this paper, we will use the term "misconception" to refer to a situation where someone holds a faulty "mental model" of real-world phenomena without realizing as much. It is important to note that misconceptions differ from dichotomous (correct vs. incorrect) evaluations of a person's thinking. Instead, they represent systematic and predictable errors in thinking that make initial conceptual sense when attempting to understand new phenomena (Smith III, diSessa, \& Roschelle, 1994).

Importantly, misconceptions about gambling appear to constitute a convincing predictor of gambling problems (Barrault \& Varescon, 2012; Devynck, Giroux, \& Jacques, 2012; Fortune \& Goodie, 2012; Joukhador, Blaszczynski, \& Maccallum, 2004; Lévesque, Sévigny, Giroux, \& Jacques, 2018; Mathieu, Barrault, Brunault, \& Varescon, 2018; Miller \& Currie, 2008; Oei, Lin, \& Raylu, 2008; Toneatto, 1999; Toneatto, Blitz-Miller, Calderwood, Dragonetti, \&
Tsanos, 1997; Toplak, Liu, Macpherson, Toneatto, \& Stanovich, 2007) as well as among adolescents (Cosenza \& Nigro, 2015; Donati et al., 2018). This research suggests that gambling-related misconceptions serve an important developmental role in the learning process gamblers undergoes during some of their first early gambling experiences, and may provide a fruitful avenue for early intervention or prevention of gambling problems.

While gamblers with and without problems possess misconceptions, those with problems express such cognitions more frequently and more intensely than those without problems (Baboushkin et al., 2001; Joukhador et al., 2004; Raylu \& Oei, 2004). Interestingly, recent research has suggested that gambling misconceptions may moderate or mediate the effects of other risk factors on gambling problems (Lévesque et al., 2018; Miller \& Currie, 2008; Wong, Zhuang, Jackson, Dowling, \& Lo, 2018). In addition, Mathieu et al. (2018) studied gambling motives of male poker players and determined that their data were consistent with a process model of gambling where gambling motives led to practice, which increased risk of developing misconceptions, which predicted problems.

\section{What do gambling-related misconceptions look like?}

Three recent reviews provide an overview of gamblingrelated misconceptions (Ejova \& Ohtsuka, 2019; Fortune \& Goodie, 2012; Leonard, Williams, \& Vokey, 2015). Although there are several different and nuanced gambling misconceptions, there appears to be three broad categories of misconceptions, which appear to influence gambling behavior, each of which may manifest in different ways depending on the individual, the gambling environment, and the type of gambling game (Lévesque, Sévigny, Giroux, \& Jacques, 2017). The following broad categories of misconceptions are described below, and their origins and manifestations are discussed later in this section.

The gambler's fallacy. Also known as the Monte Carlo Fallacy, refers to the mistaken belief that after a series of losses a win is more likely [e.g., in electronic gaming machine (EGM) play "I have lost $\$ 500$ on this machine, therefore a win is due soon"], or after a series of one particular outcome, the alternate outcome is more likely (e.g., in roulette: "it's landed on red the last ten spins! It's got to be black next"). This has also been associated with more broad decision-making biases, such as representativeness (see Fortune \& Goodie, 2012 for an explanation of how this relates to the gambler's fallacy).

The hot hand fallacy. This fallacy refers to the belief that a winning streak is an indication of more winning. That is, an EGM might be considered to be "hot" or a player "on a roll" when incurring several wins in a row, which inclines players to persist playing while the "winning streak" is occurring.

Illusion of control. This refers to the propensity to believe that the player has some level of control over chance outcomes, and that their personal level of success is higher than objective probability would suggest. For example, that choosing your own lottery numbers or rolling your own dice (as opposed to having them chosen randomly or thrown for you) will improve your likelihood of winning. 
Although this is not an extensive list of the kinds of misconceptions problem gamblers may have, these three broad cognitions can be considered umbrella terms for some more specific misconceptions gamblers may hold. For example, a gambler's specific thought "I'm on a roll" pertains to the hot hand fallacy, whereas the thought "I'm getting good at this" is a manifestation of the illusion of control. Exactly where these misconceptions come from is of key importance to understanding how they might influence behavior, and how we might go about preventing them.

Accounting for the origins of gambling misconceptions has the potential to increase young people's engagement with prevention by accounting for some early developmental stages that occur between non-gambling and problem gambling. It is possible that identification with the early stages of non-problem gambling may increase message relevance from young people who may then be more receptive to subsequent educational material. It is also important to determine temporally when gamblers are likely to develop these misconceptions, so that we can determine an appropriate strategy for prevention.

\section{Where do gambling-related misconceptions come from?}

There are several known cognitive biases and heuristics, which broadly affect our decision-making and likely play a role in the development of gambling-related misconceptions (see Kahneman \& Tversky, 1972; Tversky \& Kahneman, 1973, 1974). However, more specifically, as misconceptions develop from attempts to learn new phenomena, gamblingrelated misconceptions appear to be derived directly from ineffective attempts to understand gambling outcomes.

Ejova and Ohtsuka (2019) contended that gambling misconceptions emerge from misapplying conventional heuristics when attempting to solve problem on how to win money gambling. The authors suggest that gamblers bring their preconceived belief systems to this problem-solving process, which can relate to the natural world, supernatural phenomena, and understanding of random processes. Combined with work in reinforcement learning, the authors provided an account for why the gambler's fallacy is often present but does not lead to gambling problems for most gamblers. Experimental work carried out by Redish, Jensen, Johnson, and Kurth-Nelson (2007) determined that significant wins represent a large salient "strike" to the gamblers' learning process, which is largely impervious to extinction effects. One possible conclusion from this research suggests that winning may facilitate the misapplication of the gambler's fallacy to future gambling decisions, encouraging continued gambling despite losses and eventually leading to gambling problems.

Early wins. Early positive gambling experiences such as a big win have been associated with an increased risk of developing gambling misconceptions and problems (Cummins, Nadorff, \& Kelly, 2009; Delfabbro et al., 2005; Delfabbro \& Thrupp, 2003; Lambos, Delfabbro, \& Puglies, 2007; Langer \& Roth, 1975; Lesieur, 1984; Moran, 1970; Turner, Jain, Spence, \& Zangeneh, 2008). It is possible that positive early gambling experiences may lead gamblers to develop a strong association between gambling and winning, and this may promote or strengthen biases toward decisions to gamble beyond affordable limits. Although this notion has not been tested in detail, there is some evidence that this is the case; problem gamblers are more likely to report being motivated to gamble to win money (Lee, Chae, Lee, \& Kim, 2007), and gamblers motivated to win money are more likely to engage in loss chasing behavior (Lister, Nower, \& Wohl, 2016). This emphasizes the need to intervene early, prior to gambling experiences to prevent misconceptions from developing.

Underlying game mathematics. Extensive research carried out by educators and cognitive psychologists indicates that young people possess numerous misconceptions about scientific phenomena. Such misconceptions have been demonstrated in samples of students studying physics (Clement, 1982; Loverude, Kautz, \& Heron, 2003; Zeineddin \& Abd-El-Khalick, 2010), mechanical and electrical engineering (Chen, Pan, Sung, \& Chang, 2013; Nelson et al., 2017; Wettergren, 2002), evolutionary biology (Chi, Kristensen, \& Roscoe, 2012; Evans, 2008; Heddy \& Sinatra, 2013), and most important to gambling, mathematics (Confrey, 1990; Garfield \& Ahlgren, 1988; Gürbüz \& Birgin, 2012; Shaughnessy, 1977).

The root of these misconceptions has been described as stemming from a lack of understanding of key concepts related to the subject matter. For example, students' misconceptions about buoyancy have been described as arising from an insufficient understanding of central concepts in physics, such as weight, density, force, liquid pressure and displacement, and objects in equilibrium (Loverude et al., 2003; Zeineddin \& Abd-El-Khalick, 2010). In the same way, gambling misconceptions can be described as resulting from a knowledge deficit of specific concepts in mathematics, including randomness, probabilities, and negative expected return (the unprofitability of gambling games; Blaszczynski \& Nower, 2002; Gaboury \& Ladouceur, 1989; Hardoon, Baboushkin, Derevensky, \& Gupta, 2001; Ladouceur \& Walker, 1996; Sharpe, 2002; Toplak et al., 2007; Walker, 1992b). Improving understanding of the mathematical underpinnings of commercial gambling products has been described as an important strategy to promote responsible attitudes toward gambling and prevent harm (Blaszczynski et al., 2015; Lowe \& Money, 2017; Peard, 2008). Indeed, even outside the gambling literature, educators have suggested that necessary prerequisites to remediation of misconceptions like the gambler's fallacy involve education around concepts of independence and mathematical expectation (Peard, 2008).

\section{RECOMMENDATION 3: EDUCATE ABOUT GAMBLING MATHEMATICS TO PREVENT HARM}

A number of empirical studies have concluded that misunderstanding gambling-related mathematics concepts plays an important role in the development and maintenance of gambling problems, and that better understanding these might help prevent the onset of problems (Donati et al., 2018; Ferland, Ladouceur, \& Vitaro, 2002; Ladouceur, Ferland, \& Vitaro, 2004; Ladouceur, Ferland, Vitaro, \& 
Pelletier, 2005; Lavoie \& Ladouceur, 2004). However, not all findings have been positive. For example, Lambos and Delfabbro (2007) found no difference in numeric reasoning and ability between pathological, recreational, and non-gamblers and concluded that educating about odds was unlikely to be effective in minimizing gambling-related harm. Similarly, Williams and Connolly (2006) found that educating about mathematical knowledge relating to gambling did not result in predicted behavior change.

Researchers have argued that part of the difficulty in impacting behavior by altering gambling cognitions is that gamblers seem to have a rational understanding of the unprofitability of gambling outside of gambling sessions, but due to emotional investment in the game, they "switch" back to unhelpful belief systems during a gambling session (Sevigny \& Ladouceur, 2003). Australian researchers (Delfabbro, Lahn, \& Grabosky, 2006; Delfabbro, Lambos, et al., 2009) referred to this concept in two studies of adolescent gamblers and demonstrated that despite adolescent problem gamblers' misconceptions of randomness, they did not differ from non-problem gamblers in terms of their objective understanding of gambling odds. Educational programs for adolescents and young adults have attempted to address the role of emotions by incorporating emotion-skills training. For example, Romanian researchers (Lupu \& Lupu, 2013; Todirita \& Lupu, 2013) incorporated Rational Emotive Education with gambling education, which resulted in improvements to gambling knowledge, misconceptions, and attitudes. However, it is not known what component of the education was most effective (emotion skills, game design knowledge, or some combination of both).

These challenges are consistent with studies in the pedagogical literature, which suggests that when teaching abstract and complex scientific concepts, information about the concept is often insufficient to challenge previously held misconceptions. Loverude et al. (2003) investigated physics student's understanding of Archimedes' principle and determined that standard instruction on hydrostatics was insufficient to combat prior misconceptions and often left students confused about the new information. Similarly, Zeineddin and Abd-El-Khalick (2010) concluded that even among college students, prior knowledge played an important and potentially damaging role in their scientific reasoning skills. The authors explained that even after providing students with the correct information (Archimedes' principle), students did not revise or change their original misconceptions. Importantly, we echo the arguments put forward by gambling researchers Wohl, Christie, Matheson, and Anisman (2010), who suggest that presenting factual information alone may not be sufficient for teaching complex ideas, particularly when that information does not sit within an existing knowledgebase (i.e., is not personally relevant).

It appears then that the challenging task is to teach young people difficult mathematics concepts specific to gambling, so that they do not develop problematic misconceptions, which place them at risk of gambling problems. However, it is not clear how we should go about doing so in a way that will maximize learning outcomes for young people. Furthermore, it appears that merely presenting factual information may be insufficient to combat misconceptions. Fortunately, the pedagogical literature constitutes a largely untapped resource providing a wealth of recommendations for how best to teach young people complex material that is prone to misconceptions.

\section{Early learning processes and conceptual change}

Emphasizing the importance of prior knowledge, Posner, Strike, Hewson, and Gertzog (1982) adapted Thomas Kuhn's (1962) original work on theory change in science to describe the application of conceptual change in science education. This model provides an account for how learners shift from an initial set of concepts to a new set that are incompatible with the first. Posner et al. (1982) suggested four specific criteria necessary for a learner to forego their prior conceptual knowledge and adopt new incompatible ideas. The authors suggest that before new concepts can be adopted, there must be (a) dissatisfaction with the current conception and the new conception must be (b) intelligible, (c) plausible, and (d) able to resolve the problems of the original one (Posner et al., 1982).

More recently, Chi et al. (2012) adapted Posner et al.'s (1982) work in conceptual change and provided a concordant account for why many scientific phenomena are difficult to learn and how misconceptions develop. The authors suggest that as children, we construct our worldview using examples from experiences in our everyday life. They term this internal structure a "Direct Causal Schema" because it refers to processes that are sequential in nature, where one event builds upon another, and is directly causally related to the other. Examples of sequential processes learned in school include those that refer to cyclical or stage-like phenomena, such as learning the phases of the moon, stages of human development, and the various stages of photosynthesis (Chi et al., 2012). The authors suggest that we attempt to assimilate new information into this existing schema when learning new phenomena, and that for the above examples, this is mostly appropriate. However, many concepts in science entail non-sequential processes (e.g., randomness). Similar to the misapplication of conventional heuristics described by Ejova and Ohtsuka (2019), Chi et al. (2012) explain how misconceptions can develop from attempts to apply a direct causal schema to nonsequential processes.

In Heddy and Sinatra's (2013) study of undergraduate students' misconceptions about evolutionary biology, the authors described how evolutionary concepts often conflict with our intuitive feelings of agency and purposiveness. The researchers argued that such intuitions usually help construct meaning in the face of complex information; however, when learning new concepts related to evolution, they impeded student's ability to understand the content fully.

Comparisons can be drawn here with gambling education. Complex and abstract mathematical concepts that underpin the operation of gambling games can be considered non-sequential, and indeed the process of how an EGM produces a winning outcome for a player is a non-sequential process. Using Chi et al.'s (2012) framework, we can describe how novice gamblers may apply a direct causal schema when attempting to understand how and when EGMs produce winning outcomes. For example, the gambler's fallacy can be described as resulting from an attempt 
to apply a direct causal schema (processes occur in a cumulative/cyclic fashion) to a non-sequential process (machines operate randomly, and every spin is independent of the last).

Using misconceptions as a didactic technique to enhance learning gambling mathematics

Applications of the conceptual change framework suggest that misconceptions play an important role in learning new and complex information. In particular, educating about misconceptions represents an important opportunity for learners to consider the failures of that concept, and prepares them to better accurately accept new complex information (Chi \& Roscoe, 2002; Chi, Slotta, \& De Leeuw, 1994; Posner et al., 1982; Strike \& Posner, 1982). However, this must be done strategically; it is best to first specify misconceptions, encourage dissatisfaction with those ideas, and then provide information, which remediates them and provides more fruitful outcomes (Posner et al., 1982; Strike \& Posner, 1982).

Of note, there is increasing evidence that targeting misconceptions in gambling education may be effective. Donati et al. (2018) reported on two studies; the first of which determined that misconceptions were a significant predictor of gambling problems among adolescents. Following this finding, the authors designed an education program, which instructed adolescents to reflect on the irrationality of probabilistic reasoning errors and superstitious thinking. The results of this education program indicated a successful reduction in misconceptions and gambling frequency compared to adolescents who did not receive the program (Donati et al., 2018).

\section{RECOMMENDATION 4: LEVERAGE TECHNOLOGY TO TEACH COMPLEX CONCEPTS}

Teaching key mathematical concepts at the level of depth required for comprehension is difficult, and educators are already required to teach outside their scope of knowledge (Batanero \& Diaz, 2012; Garfield \& Ahlgren, 1988). Consequently, educators often provide only superficial explanations of what are reasonably complex concepts, which likely impedes uptake of new information (Schwartz, Varma, \& Martin, 2008). This may explain why some researchers have concluded that teaching such concepts is unlikely to reduce gambling-related harm (e.g., Lambos \& Delfabbro, 2007). That is, it is not clear if teaching such concepts is ineffective in preventing harm, or if the concepts, because of their inherent difficulty, are not being adequately taught.

Most evaluated gambling prevention programs provide superficial explanations of the mathematical concepts that underlie problematic misconceptions about commercial gambling (Keen et al., 2016). Educators have stressed that a more comprehensive understanding of these concepts is needed to reinforce responsible attitudes toward gambling, and that such concepts can be readily learnt by those with little prior success in mathematics (Peard, 2008). Superficial explanations of new concepts are likely to raise skepticism among learners, and unless new concepts are explained in sufficient and compelling detail, learners will likely reject the information and hold on to any previously held convictions, regardless of their accuracy (Posner et al., 1982; Smith III et al., 1994; Strike \& Posner, 1982). For example, telling a problem gambler who holds the misconception that gaming machines operate in winning and losing cycles that machines are actually random may not adequately compel them to accept that notion without sufficient explanation.

Pedagogical researchers have suggested that teaching complex mathematical concepts can be enhanced using newly available technologies (Borovcnik, 2007; Chandra \& Watters, 2012; McKagan et al., 2008). For example, computer-generated visualizations and animations are powerful tools that can be leveraged to help explain complex abstract concepts necessary for inclusion in problem gambling education; and students now have access to point-and-click software to perform data simulations that allow them to visualize and understand abstract statistical problems (Borovcnik, 2007). Previous research has demonstrated that computer simulations and visualizations facilitate learning complex and abstract concepts in science, such as those in electronics, engineering, quantum mechanics, physics, and mathematics - including remediation of misconceptions about probabilities (Borovcnik, 2007; Chandra \& Watters, 2012; Gürbüz \& Birgin, 2012; Mayer \& Moreno, 2002; McKagan et al., 2008; Nelson et al., 2017; Özyurt, Özyurt, Güven, \& Baki, 2014; Pilli \& Aksu, 2013). Such simulations can also be displayed in graph format for visual impact.

For these reasons, it may be appropriate to incorporate gambling education into school mathematics curricula. Information learned in mathematics classes relating to probabilities, randomness, and expected value may be appropriately applied to gambling games to expose misconceptions, which motivate gambling play. Members of the Mathematics Association of Victoria (MAV) in Australia have recently worked closely with the Victorian Responsible Gambling Fund to develop gambling education units that sit within the current mathematics curriculum and specifically address the concepts of independence of events and long-term negative payoff, and how these concepts refute problematic gambling misconceptions (Lowe \& Money, 2017). The units include data simulations and visualizations of gambling outcomes, and examples of EGM gambling, sports betting, and card play to demonstrate how gambling losses can be predicted in the long term. Mathematics educators have suggested that such programs from the MAV are likely to have a stronger impact on preventing gambling-related harm compared to those which focus on promoting the harms (Barboianu, 2013; Peard, 2008).

The ability to visualize gambling outcomes in the long term via simulations is critical to promoting deep learning of challenging mathematical concepts (Borovenik, 2007; Gürbüz \& Birgin, 2012; McKagan et al., 2008; Özyurt et al., 2014; Pilli \& Aksu, 2013). Simulations can be run and the output is shown in graph, so that learners can visualize how outcomes converge on the expected value over time. Adjustments can then be made to various parameters of the simulated gambling game (e.g., bet size), so that learners can gain a better appreciation for long-term play. 
One further benefit of utilizing computer-assisted technologies in problem gambling education is that it helps control for educator effects. That is, computer-based programs represent standardized instruction. This is a compelling advantage, given the low mathematical literacy among some teachers, the difficulty inherent in teaching these concepts, and the already overflowing curriculum schools are expected to deliver (Batanero \& Diaz, 2012; Garfield \& Ahlgren, 1988).

\section{CONCLUSIONS FOR RECOMMENDED IMPROVEMENTS TO GAMBLING EDUCATION}

This paper suggests that the plethora of available psychological and pedagogical research provides a substantial foundation to improve the design of gambling educational content. It should be recognized that incorporating research findings into education practice represents an iterative process where unforeseen barriers will inevitably arise and can be documented and the content modified for future adaptations. This process represents a best-practice approach to gambling education development and is illustrated in Figure 2.

Based on the above review, a number of conclusions can be drawn. A fundamental barrier to youth engagement with current programs is the lack of a detailed description of problem gambling development, which ultimately prevents audiences from relating to the disorder. From a cognitive perspective, problem gambling development arises in large part from misconceptions, and the inclusion of misconceptions in educational programs could enhance learning engagement and outcomes. However, such inclusion raises further challenges as misconceptions relate to abstract mathematical concepts that underpin commercial gambling products but are complex and difficult to teach.

The pedagogical literature provides helpful avenues to teaching complex and abstract concepts, which are prone to misconceptions. It suggests exposing misconceptions represents a didactic technique whereby learners are able to consider their problematic nature, and ultimately prepares them to adopt new complex corrective information. Moreover, the pedagogical literature further suggests that several technologies may be leveraged to assist in the delivery of

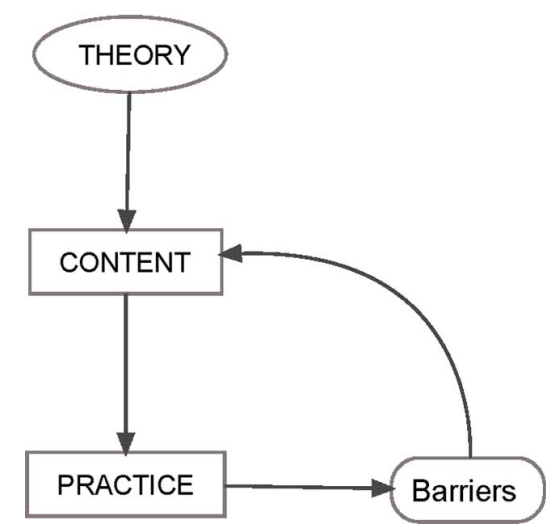

Figure 2. Proposed best-practice approach to gambling education development and implementation complex and abstract concepts in problem gambling education. The above review provides several guidelines for the development of future gambling education programs.

From a conceptual and theoretical perspective, preventive information should place less emphasis on raising awareness of severe consequences associated with gambling disorders. Fear-based approaches to problem gambling education do not resonate with young audiences and do little to effectively reduce development of gambling problems. Second, initiatives directed to adolescents should aim to include a description of problem formation that fits within a developmental framework and affords opportunities for prevention. The cognitive account of problem gambling is one such description but must include information on the etiology of gambling misconceptions.

To improve preventative outcomes of educational material, content should focus on gambling-related mathematical concepts that are often misunderstood and lead to misconceptions about the profitability of commercial gambling games. For example, for EGMs, these concepts and their related misconceptions might include independence of events and the long-term negative expected payoff of the return-to-player percent and how these relate to the gambler's fallacy. Moreover, when attempting to teach these mathematical concepts, gambling education should teach young audiences about common misconceptions first, before presenting new complex and abstract mathematical information. A conceptual change framework suggests that misconceptions represent an opportunity for learners to consider the failures of an idea, which increase dissatisfaction with initial concepts and better prepares them to adopt new complex information.

Finally, new technologies including computer simulations and visualizations should be leveraged to help young learners comprehend new abstract mathematical concepts. Statistical simulations of gambling games over long periods of time may help to clarify how gamblers may win in the short term but ensure overall long-term losses with repeated plays. Taken together, the findings of this review have the potential to inform substantial improvements to gambling education programs that aim to prevent problems. However, it is important that these suggestions are tested empirically using robust experimental and longitudinal research methodologies and are well supported by regulatory practices and legislative policies.

Funding sources: No financial support was received for this paper. This work was carried out as part of the lead author BK's doctoral thesis (unsubmitted), of which she receives scholarship payments through the Australian Department of Education and Training's Research Training Program stipend.

Authors' contribution: $\mathrm{BK}, \mathrm{FA}$, and $\mathrm{AB}$ contributed to the overall study concept and design. BK conducted the initial first drafts of the manuscript and all authors contributed in writing the final draft.

Conflict of interest: The authors declare no conflict of interest. 
Acknowledgements: The authors would like to acknowledge assistance from Martin Wieczorek on early edits and revisions of this manuscript, which ultimately helped inform the current version.

\section{REFERENCES}

Baboushkin, H. R., Hardoon, K. K., Derevensky, J. L., \& Gupta, R. (2001). Underlying cognitions in gambling behavior among university students. Journal of Applied Social Psychology, 31(7), 1409-1430. doi:10.1111/j.1559-1816.2001. tb02680.x

Bachman, J. G., Freedman-Doan, P., Schulenberg, J. E., Messersmith, E. E., O’Malley, P. M., \& Johnston, L. D. (2008). The educationdrug use connection: How successes and failures in school relate to adolescent smoking, drinking, drug use, and delinquency. New York, NY: Psychology Press.

Barboianu, C. (2013). Mathematician's call for interdisciplinary research effort. International Gambling Studies, 13(3), 430-433. doi:10.1080/14459795.2013.837087

Barrault, S., \& Varescon, I. (2012). Distorsions cognitives et pratique de jeu de hasard et d'argent: État de la question [Cognitive distortions and gambling behaviours: State of the question]. Psychologie Française, 57(1), 17-29. doi:10.1016/ j.psfr.2012.01.002

Batanero, C., \& Diaz, C. (2012). Training school teachers to teach probability: Reflections and challenges. Chilean Journal of Statistics, 3(1), 3-13. Retrieved from http://chjs.mat.utfsm.cl/ volumes/03/01/Batanero_Diaz(2012).pdf

Blaszczynski, A., Anjoul, F., Shannon, K., Keen, B., Pickering, D., \& Wieczorek, M. (2015). Gambling harm minimisation report. NSW Government Department of Trade \& Investment Office of Liquor, Gambling and Racing. Retrieved from https://www. liquorandgaming.nsw.gov.au/Documents/gaming-and-wagering/ problems-with-gambling/research/gambling-harm-minimisationreport.pdf

Blaszczynski, A., \& Nower, L. (2002). A pathways model of problem and pathological gambling. Addiction, 97(5), 487-499. doi:10.1046/j.1360-0443.2002.00015.x

Borovcnik, M. (2007). New technologies revolutionize the applications of statistics and its teaching. Paper presented at 56th session of the Bulletin of the International Statistical Institute, Lisbon, Portugal.

Chandra, V., \& Watters, J. J. (2012). Re-thinking physics teaching with web-based learning. Computers \& Education, 58(1), 631-640. doi:10.1016/j.compedu.2011.09.010

Chen, Y.-L., Pan, P.-R., Sung, Y.-T., \& Chang, K.-E. (2013). Correcting misconceptions on electronics: Effects of a simulationbased learning environment backed by a conceptual change model. Educational Technology \& Society, 16(2), 212-227.

Chi, M. T. H., Kristensen, A. K., \& Roscoe, R. D. (2012). Misunderstanding emergent causal mechanism in natural selection. In K. S. Rosengren, S. K. Brem, E. M. Evans, \& G. M. Sinatra (Eds.), Evolution challenges: Integrating research and practice in teaching and learning about evolution. Oxford, UK: Oxford University Press.

Chi, M. T. H., \& Roscoe, R. D. (2002). The processes and challenges of conceptual change. In M. Limón \& L. Mason (Eds.), Reconsidering conceptual change: Issues in theory and practice (pp. 3-27). Dordrecht, The Netherlands: Kluwer Academic Publishers.

Chi, M. T. H., Slotta, J. D., \& De Leeuw, N. (1994). From things to processes: A theory of conceptual change for learning science concepts. Learning and Instruction, 4(1), 27-43. doi:10.1016/ 0959-4752(94)90017-5

Chretien, M., Giroux, I., Goulet, A., Jacques, C., \& Bouchard, S. (2017). Cognitive restructuring of gambling-related thoughts: A systematic review. Addictive Behaviors, 75, 108-121. doi:10.1016/j.addbeh.2017.07.001

Clement, J. (1982). Students' preconceptions in introductory mechanics. American Journal of Physics, 50(1), 66-71. doi:10.1119/ 1.12989

Confrey, J. (1990). A review of the research on student conceptions in mathematics, science, and programming. Review of Research in Education, 16(1), 3-56. doi:10.3102/0091732X 016001003

Cosenza, M., \& Nigro, G. (2015). Wagering the future: Cognitive distortions, impulsivity, delay discounting, and time perspective in adolescent gambling. Journal of Adolescence, 45, 56-66. doi:10.1016/j.adolescence.2015.08.015

Cummins, L. F., Nadorff, M. R., \& Kelly, A. E. (2009). Winning and positive affect can lead to reckless gambling. Psychology of Addictive Behaviors, 23(2), 287-294. doi:10.1037/a0014783

Delfabbro, P., Lahn, J., \& Grabosky, P. (2005). Further evidence concerning the prevalence of adolescent gambling and problem gambling in Australia: A study of the ACT. International Gambling Studies, 5(2), 209-228. doi:10.1080/14459790500 303469

Delfabbro, P., Lahn, J., \& Grabosky, P. (2006). It's not what you know, but how you use it: Statistical knowledge and adolescent problem gambling. Journal of Gambling Studies, 22(2), 179-193. doi:10.1007/s10899-006-9009-5

Delfabbro, P., Lambos, C., King, D., \& Puglies, S. (2009). Knowledge and beliefs about gambling in Australian secondary school students and their implications for education strategies. Journal of Gambling Studies, 25(4), 523-539. doi:10.1007/s10899-009-9141-0

Delfabbro, P., \& Thrupp, L. (2003). The social determinants of youth gambling in South Australian adolescents. Journal of Adolescence, 26(3), 313-330. doi:10.1016/S0140-1971(03) 00013-7

Delfabbro, P., \& Winefield, A. (2000). Predictors of irrational thinking in regular slot machine gamblers. The Journal of Psychology, 134(2), 117-128. doi:10.1080/0022398000960 0854

Delfabbro, P., Winefield, A. H., \& Anderson, S. (2009). Once a gambler - Always a gambler? A longitudinal analysis of gambling patterns in young people making the transition from adolescence to adulthood. International Gambling Studies, 9(2), 151-163. doi:10.1080/14459790902755001

Derevensky, J. L., \& Gupta, R. (2000). Prevalence estimates of adolescent gambling: A comparison of the SOGS-RA, DSMIV-J, and the GA 20 questions. Journal of Gambling Studies, 16(2), 227-251. doi:10.1023/A:1009485031719

Derevensky, J. L., Gupta, R., \& Winters, K. (2003). Prevalence rates of youth gambling problems: Are the current rates inflated? Journal of Gambling Studies, 19(4), 405-425. doi:10.1023/A:1026379910094

Devynck, F., Giroux, I., \& Jacques, C. (2012). Les distorsions cognitives [Cognitive distortions]. In M. Bronnec-Grall (Ed.), 
Le Jeu Pathologique [Pathological gambling: Understand prevent - treat] (pp. 75-80). Issy-les-Moulineaux, France: Elsevier-Masson.

Donati, M. A., Chiesi, F., Iozzi, A., Manfredi, A., Fagni, F., \& Primi, C. (2018). Gambling-related distortions and problem gambling in adolescents: A model to explain mechanisms and develop interventions. Frontiers in Psychology, 8, 2243. doi:10.3389/fpsyg.2017.02243

Ejova, A., \& Ohtsuka, K. (2019). Erroneous gambling-related beliefs emerge from broader beliefs during problem-solving: A critical review and classification scheme. Thinking \& Reasoning. Advance online publication. 1-29. doi:10.1080/ 13546783.2019.1590233

Evans, E. M. (2008). Conceptual change and evolutionary biology: A developmental analysis. In S. Vosniadou (Ed.), International handbook of research on conceptual change (pp. 263-294). New York, NY: Taylor \& Francis.

Ferland, F., Ladouceur, R., \& Vitaro, F. (2002). Prevention of problem gambling: Modifying misconceptions and increasing knowledge. Journal of Gambling Studies, 18(1), 19-29. doi:10.1023/A:1014528128578

Fortune, E. E., \& Goodie, A. S. (2012). Cognitive distortions as a component and treatment focus of pathological gambling: A review. Psychology of Addictive Behaviors, 26(2), 298-310. doi:10.1037/a0026422

Gaboury, A., \& Ladouceur, R. (1989). Erroneous perceptions and gambling. Journal of Social Behavior and Personality, 4(4), 411.

Garfield, J., \& Ahlgren, A. (1988). Difficulties in learning basic concepts in probability and statistics: Implications for research. Journal for Research in Mathematics Education, 19(1), 44-63. doi: $10.2307 / 749110$

Goldberg, L., Bents, R., Bosworth, E., Trevisan, L., \& Elliot, D. L. (1991). Anabolic steroid education and adolescents: Do scare tactics work? Pediatrics, 87(3), 283-286.

Griffiths, M. (1994). The role of cognitive bias and skill in fruit machine gambling. British Journal of Psychology, 85(3), 351-369. doi:10.1111/j.2044-8295.1994.tb02529.x

Gupta, R., Nower, L., Derevensky, J. L., Blaszczynski, A., Faregh, N., \& Temcheff, C. (2013). Problem gambling in adolescents: An examination of the pathways model. Journal of Gambling Studies, 29(3), 575-588. doi:10.1007/s10899-012-9322-0

Gürbüz, R., \& Birgin, O. (2012). The effect of computer-assisted teaching on remedying misconceptions: The case of the subject "probability". Computers \& Education, 58(3), 931-941. doi:10.1016/j.compedu.2011.11.005

Hardoon, K. K., Baboushkin, H. R., Derevensky, J. L., \& Gupta, R. (2001). Underlying cognitions in the selection of lottery tickets. Journal of Clinical Psychology, 57(6), 749-763. doi:10.1002/ jclp. 1047

Hastings, G., Stead, M., \& Webb, J. (2004). Fear appeals in social marketing: Strategic and ethical reasons for concern. Psychology \& Marketing, 21(11), 961-986. doi:10.1002/mar.20043

Heddy, B. C., \& Sinatra, G. M. (2013). Transforming misconceptions: Using transformative experience to promote positive affect and conceptual change in students learning about biological evolution. Science Education, 97(5), 723-744. doi:10.1002/ sce. 21072

Higbee, K. L. (1969). Fifteen years of fear arousal: Research on threat appeals: 1953-1968. Psychological Bulletin, 72(6), 426-444. doi:10.1037/h0028430
Joukhador, J., Blaszczynski, A., \& Maccallum, F. (2004). Superstitious beliefs in gambling among problem and nonproblem gamblers: Preliminary data. Journal of Gambling Studies, 20(2), 171-180. doi:10.1023/B:JOGS.0000022308. $27774.2 b$

Kahneman, D., \& Tversky, A. (1972). Subjective probability: A judgment of representativeness. Cognitive Psychology, 3(3), 430-454. doi:10.1016/0010-0285(72)90016-3

Keen, B., Blaszczynski, A., \& Anjoul, F. (2016). Systematic review of empirically evaluated school-based gambling education programs. Journal of Gambling Studies, 33(1), 301-325. doi:10.1007/s10899-016-9641-7

Kuhn, T. S. (1962). The structure of scientific revolutions (2nd ed.). Chicago, IL/London, UK: University of Chicago Press.

Ladouceur, R., Ferland, F., \& Vitaro, F. (2004). Prevention of problem gambling: Modifying misconceptions and increasing knowledge among Canadian youths. Journal of Primary Prevention, 25(3), 329-335. doi:10.1023/B:JOPP.0000048024. 37066.32

Ladouceur, R., Ferland, F., Vitaro, F., \& Pelletier, O. (2005). Modifying youths' perception toward pathological gamblers. Addictive Behaviors, 30(2), 351-354. doi:10.1016/j.addbeh. 2004.05.002

Ladouceur, R., Goulet, A., \& Vitaro, F. (2013). Prevention programmes for youth gambling: A review of the empirical evidence. International Gambling Studies, 13(2), 141-159. doi:10.1080/14459795.2012.740496

Ladouceur, R., \& Walker, M. B. (1996). A cognitive perspective on gambling. In P. M. Salkovis (Ed.), Trends in cognitive and behavioural therapies. London, UK: John Wiley.

Lambos, C., \& Delfabbro, P. (2007). Numerical reasoning ability and irrational beliefs in problem gambling. International Gambling Studies, 7(2), 157-171. doi:10.1080/14459790701387428

Lambos, C., Delfabbro, P., \& Puglies, S. (2007). Adolescent gambling in South Australia. Department for Education and Children's Services. Retrieved from http://www.researchgate. net/profile/Paul_Delfabbro/publication/242769067_Adolescent_ Gambling_in_South_Australia/links/0c9605293bbe4e8574000 000.pdf

Langer, E. J., \& Roth, J. (1975). Heads I win, tails it's chance: The illusion of control as a function of the sequence of outcomes in a purely chance task. Journal of Personality and Social Psychology, 32(6), 951-955. doi:10.1037/0022-3514.32.6.951

Lavoie, M.-P., \& Ladouceur, R. (2004). Prevention of gambling among youth: Increasing knowledge and modifying attitudes toward gambling. Journal of Gambling Issues, (10), 10-19. doi:10.4309/jgi.2004.10.7

Lee, H.-P., Chae, P. K., Lee, H.-S., \& Kim, Y.-K. (2007). The fivefactor gambling motivation model. Psychiatry Research, 150(1), 21-32. doi:10.1016/j.psychres.2006.04.005

Leonard, C. A., Williams, R. J., \& Vokey, J. (2015). Gambling fallacies: What are they and how are they best measured? Addiction Research and Therapy, 6(4), 1-9. doi:10.4172/21556105.1000256

Lesieur, H. (1984). The chase: Career of the compulsive gambler. Contemporary Sociology, 10(2), 232-233. doi:10.2307/ 2066881

Lévesque, D., Sévigny, S., Giroux, I., \& Jacques, C. (2017). Gambling-Related Cognition Scale (GRCS): Are skills-based games at a disadvantage? Psychology of Addictive Behaviors, 31(6), 647-654. doi:10.1037/adb0000297 
Lévesque, D., Sévigny, S., Giroux, I., \& Jacques, C. (2018). Psychological vulnerability and problem gambling: The mediational role of cognitive distortions. Journal of Gambling Studies, 34(3), 807-822. doi:10.1007/s10899-017-9740-0

Lister, J. J., Nower, L., \& Wohl, M. J. A. (2016). Gambling goals predict chasing behavior during slot machine play. Addictive Behaviors, 62, 129-134. doi:10.1016/j.addbeh.2016.06.018

Loverude, M. E., Kautz, C. H., \& Heron, P. R. L. (2003). Helping students develop an understanding of Archimedes' principle. I. Research on student understanding. American Journal of Physics, 71(11), 1178-1187. doi:10.1119/1.1607335

Lowe, I., \& Money, R. (2017). Gambling and mathematics education. Vinculum, 54(1), 5-9.

Lupu, I. R., \& Lupu, V. (2013). Gambling prevention program for teenagers. Journal of Cognitive and Behavioral Psychotherapies, 13(2a), 575-584. Retrieved from researchgate.net/ publication/289350446_Gambling_prevention_program_for_ teenagers

Martin, I. M., \& Kamins, M. A. (2010). An application of terror management theory in the design of social and health-related anti-smoking appeals. Journal of Consumer Behaviour, 9(3), 172-190. doi:10.1002/cb.293

Mathieu, S., Barrault, S., Brunault, P., \& Varescon, I. (2018). Gambling motives: Do they explain cognitive distortions in male poker gamblers? Journal of Gambling Studies, 34(1), 133-145. doi:10.1007/s10899-017-9700-8

Mayer, R. E., \& Moreno, R. (2002). Animation as an aid to multimedia learning. Educational Psychology Review, 14(1), 87-99. doi:10.1023/A:1013184611077

McIntosh, C. (2017). Problem gambling treatment background. In K. O'Neill \& C. McIntosh (Eds.), Evidence-based treatments for problem gambling (p. 102). Cham, Switzerland: Springer.

McKagan, S. B., Perkins, K. K., Dubson, M., Malley, C., Reid, S., LeMaster, R., \& Weiman, C. E. (2008). Developing and researching $\mathrm{PhET}$ simulations for teaching quantum mechanics. American Journal of Physics, 76(4), 406-417. doi:10.1119/1.2885199

Miller, N. V., \& Currie, S. R. (2008). A Canadian population level analysis of the roles of irrational gambling cognitions and risky gambling practices as correlates of gambling intensity and pathological gambling. Journal of Gambling Studies, 24(3), 257-274. doi:10.1007/s10899-008-9089-5

Monaghan, S. (2008). Role of education in the prevention of youth gambling problems (p. 23). A report prepared for the Australasian Gaming Council, Melbourne, VIC.

Moran, E. (1970). Gambling as a form of dependence. The British Journal of Addiction to Alcohol and Other Drugs, 64(3), 419-428. doi:10.1111/j.1360-0443.1970.tb03705.x

Nelson, K. G., McKenna, A. F., Brem, S. K., Hilpert, J., Husman, J., \& Pettinato, E. (2017). Students' misconceptions about semiconductors and use of knowledge in simulations. Journal of Engineering Education, 106(2), 218-244. doi:10.1002/ jee. 20163

Noar, S. M., Palmgreen, P., Chabot, M., Dobransky, N., \& Zimmerman, R. S. (2009). A 10-year systematic review of HIV/AIDS mass communication campaigns: Have we made progress? Journal of Health Communication, 14(1), 15-42. doi:10.1080/10810730802592239

Oei, T. P., Lin, J., \& Raylu, N. (2008). The relationship between gambling cognitions, psychological states, and gambling: A cross-cultural study of Chinese and Caucasians in Australia.
Journal of Cross-Cultural Psychology, 39(2), 147-161. doi:10.1177/0022022107312587

Oh, B. C., Ong, Y. J., \& Loo, J. M. Y. (2017). A review of educational-based gambling prevention programs for adolescents. Asian Journal of Gambling Issues and Public Health, 7(1). doi:10.1186/s40405-017-0024-5

Özyurt, Ö., Özyurt, H., Güven, B., \& Baki, A. (2014). The effects of UZWEBMAT on the probability unit achievement of Turkish eleventh grade students and the reasons for such effects. Computers \& Education, 75, 1-18. doi:10.1016/j. compedu.2014.02.005

Peard, R. (2008). Teaching the mathematics of gambling to reinforce responsible attitudes towards gambling. Paper presented at the 11th International Congress on Mathematical Education, Monterrey, Mexico.

Pilli, O., \& Aksu, M. (2013). The effects of computer-assisted instruction on the achievement, attitudes and retention of fourth grade mathematics students in North Cyprus. Computers \& Education, 62, 62-71. doi:10.1016/j.compedu. 2012.10.010

Posner, G. J., Strike, K. A., Hewson, P. W., \& Gertzog, W. A. (1982). Accommodation of a scientific conception: Toward a theory of conceptual change. Science Education, 66(2), 211-227. doi:10.1002/sce.3730660207

Productivity Commission. (2010). Gambling. Canberra, Australia: Productivity Commission.

Purdie, N., Matters, G., Hillman, K., Ozolins, C., \& Millwood, P. (2011). Gambling and young people in Australia. Report prepared for Gambling Research Australia. Retrieved from http:// www.gamblingresearch.org.au/home/research/gra+research+ reports/gambling+and+young+people+in+australia+\%2820 $11 \% 29$

Raylu, N., \& Oei, T. P. S. (2004). The gambling related cognitions scale (GRCS): Development, confirmatory factor validation and psychometric properties. Addiction (Abingdon, England), 99(6), 757-769. doi:10.1111/j.1360-0443.2004.00753.x

Redish, A. D., Jensen, S., Johnson, A., \& Kurth-Nelson, Z. (2007). Reconciling reinforcement learning models with behavioral extinction and renewal: Implications for addiction, relapse, and problem gambling. Psychological Review, 114(3), 784-805. doi:10.1037/0033-295X.114.3.784

Rickwood, D., Blaszczynski, A., Delfabbro, P., Dowling, N. A., \& Heading, K. (2010). The psychology of gambling (Review paper, p. 59). Australian Psychological Society. Retrieved from https://psychology.org.au/getmedia/422d3add-d12a-4427-af57bf259b056d8d/APS-gambling-paper.pdf

Schwartz, D. L., Varma, S., \& Martin, L. (2008). Dynamic transfer and innovation. In S. Vosniadou (Ed.), International handbook of research on conceptual change. New York, NY/London, UK: Routledge.

Sevigny, S., \& Ladouceur, R. (2003). Gamblers' irrational thinking about chance events: The 'double switching' concept. International Gambling Studies, 3(2), 149-161. doi:10.1080/ 1356347032000142261

Sharpe, L. (2002). A reformulated cognitive - Behavioral model of problem gambling: A biopsychosocial perspective. Clinical Psychology Review, 22(1), 1-25. doi:10.1016/S0272-7358(00) 00087-8

Shaughnessy, J. M. (1977). Misconceptions of probability: An experiment with a small-group, activity-based, model building approach to introductory probability at the college level. 
Educational Studies in Mathematics, 8(3), 295-316. doi:10.1007/BF00385927

Shernoff, D. J., Csikszentmihalyi, M., Schneider, B., \& Shernoff, E. S. (2003). Student engagement in high school classrooms from the perspective of Flow Theory. In M. Csikszentmihalyi (Ed.), Applications of flow in human development and education (pp. 475-494). Dordrecht, The Netherlands: Springer.

Smith, J. P., III, diSessa, A. A., \& Roschelle, J. (1994). Misconceptions reconceived: A constructivist analysis of knowledge in transition. Journal of the Learning Sciences, 3(2), 115-163. doi:10.1207/s15327809jls0302_1

Splevins, K., Mireskandari, S., Clayton, K., \& Blaszczynski, A. (2010). Prevalence of adolescent problem gambling, related harms and help-seeking behaviours among an Australian population. Journal of Gambling Studies, 26(2), 189-204. doi:10.1007/s10899-009-9169-1

Stinchfield, R. (2010). A critical review of adolescent problem gambling assessment instruments. International Journal of Adolescent Medicine and Health, 22(1), 77-93. Retrieved f rom https://www.researchgate.net/publication/44619701_A_ critical_review_of_adolescent_problem_gambling_assessment_ instruments

Strike, K. A., \& Posner, G. J. (1982). Conceptual change and science teaching. European Journal of Science Education, 4(3), 231-240. doi:10.1080/0140528820040302

Taylor, L., \& Parsons, J. (2011). Improving student engagement. Current Issues in Education, 14(1), 1-33. Retrieved from https:/cie.asu.edu/ojs/index.php/cieatasu/article/view/745/162

Todirita, I. R., \& Lupu, V. (2013). Gambling prevention program among children. Journal of Gambling Studies, 29(1), 161-169. doi:10.1007/s10899-012-9293-1

Toneatto, T. (1999). Cognitive psychopathology of problem gambling. Substance Use \& Misuse, 34(11), 1593-1604. doi:10.3109/10826089909039417

Toneatto, T., Blitz-Miller, T., Calderwood, K., Dragonetti, R., \& Tsanos, A. (1997). Cognitive distortions in heavy gambling. Journal of Gambling Studies, 13(3), 253-266. doi:10.1023/A: 1024983300428

Toplak, M. E., Liu, E., Macpherson, R., Toneatto, T., \& Stanovich, K. E. (2007). The reasoning skills and thinking dispositions of problem gamblers: A dual-process taxonomy. Journal of Behavioral Decision Making, 20(2), 103-124. doi:10.1002/ bdm.544

Turner, N. E., Jain, U., Spence, W., \& Zangeneh, M. (2008). Pathways to pathological gambling: Component analysis of variables related to pathological gambling. International Gambling Studies, 8(3), 281-298. doi:10.1080/1445979080 2405905
Tversky, A., \& Kahneman, D. (1973). Availability: A heuristic for judging frequency and probability. Cognitive Psychology, 5(2), 207-232. doi:10.1016/0010-0285(73)90033-9

Tversky, A., \& Kahneman, D. (1974). Judgment under uncertainty: Heuristics and biases. Science, 185(4157), 1124-1131. doi:10.1126/science.185.4157.1124

Vivancos, R., Abubakar, I., Phillips-Howard, P., \& Hunter, P. R. (2013). School-based sex education is associated with reduced risky sexual behaviour and sexually transmitted infections in young adults. Public Health, 127(1), 53-57. doi:10.1016/ j.puhe.2012.09.016

Walker, M. B. (1992a). Irrational thinking among slot machine players. Journal of Gambling Studies, 8(3), 245-261. doi:10.1007/BF01014652

Walker, M. B. (1992b). The psychology of gambling. New York, NY: Pergamon Press.

Welte, J. W., Barnes, G. M., Tidwell, M.-C. O., \& Hoffman, J. H. (2008). The prevalence of problem gambling among U. S. adolescents and young adults: Results from a national survey. Journal of Gambling Studies, 24(2), 119-133. doi:10.1007/ s10899-007-9086-0

Wettergren, J. (2002). Understanding concepts needed for semiconductor physics. European Journal of Engineering Education, 27(1), 105-111. doi:10.1080/03043790110100146

Williams, R. J., \& Connolly, D. (2006). Does learning about the mathematics of gambling change gambling behavior? Psychology of Addictive Behaviors, 20(1), 62-68. doi:10.1037/0893164X.20.1.62

Wohl, M. J. A., Christie, K.-L., Matheson, K., \& Anisman, H. (2010). Animation-based education as a gambling prevention tool: Correcting erroneous cognitions and reducing the frequency of exceeding limits among slots players. Journal of Gambling Studies, 26(3), 469-486. doi:10.1007/s10899-009-9155-7

Wong, D. F. K., Zhuang, X. Y., Jackson, A., Dowling, N., \& Lo, H. H. M. (2018). Negative mood states or dysfunctional cognitions: Their independent and interactional effects in influencing severity of gambling among Chinese problem gamblers in Hong Kong. Journal of Gambling Studies, 34(3), 631-645. doi:10.1007/s10899-017-9714-2

Yakovenko, I., Hodgins, D. C., el-Guebaly, N., Casey, D. M., Currie, S. R., Smith, G. J., Williams, R. J., \& Schopflocher, D. P. (2016). Cognitive distortions predict future gambling involvement. International Gambling Studies, 16(2), 175-192. doi:10.1080/14459795.2016.1147592

Zeineddin, A., \& Abd-El-Khalick, F. (2010). Scientific reasoning and epistemological commitments: Coordination of theory and evidence among college science students. Journal of Research in Science Teaching, 47(9), 1064-1093. doi:10.1002/ tea. 20368 